\title{
Gender Differences in Prosocial Behaviour
}

\author{
Isah Aliyu Abdullahi ${ }^{1 *}$, Dr. Pardeep Kumar ${ }^{2}$
}

\section{ABSTRACT}

The objective of current research was to examine the gender differences in prosocial behaviour. Total 60 students ( $\mathrm{N}=60,30$ Males and 30 Females) participated in the current study from Lovely Professional University, Punjab, India. The Prosocial Personality Battery (PSB) consisting seven dimensions including social responsibility (SR), emphatic concern (EC), perspective taking (PT), personal distress (PD), other oriented moral reasoning $(\mathrm{O})$, mutual concern moral reasoning (M) and self report altruism (SRA) has been used in the study to collect the data. The results revealed significant gender differences on two dimensions of prosocial personality battery, i.e. perspective taking $(\mathrm{t}=2.04, \mathrm{p}<.05)$ and other oriented moral reasoning $(\mathrm{t}$ $=2.01, \mathrm{p}<.05$ ), being females on the higher side. On rest of the five dimensions the differences were negligible falling far away from the probability level of .05. The results suggest that males and females are both almost equal on most of the prosocial behaviour dimensions. However, in case of perspective taking and mutual concern moral reasoning females are on higher side suggesting that they have better understanding of others' mental state and they are more concerned about morality in the society.

Keywords: Prosocial Behaviour, Altruism, Helping Behaviour

Prosocial behaviour is a common and important aspect of every day social life. This behaviour could be viewed as an action intended to help another person's need for support or to promote and sustain a tangible benefit for them. In other words, pro-social behaviour stem from several diverse motives and helps achieving several goals. Considerable studies shows that, through serving and volunteering, young people can convince their own need, learn and express their values, realize the world, get related experience and strengthen social competence and relationships. Individual differences are one of the crucial factors responsible for prosocial behaviour as people differ in terms of personality traits, so some people have altruistic personality others do not. Second, gender is also considered another determinant of prosocial

\footnotetext{
${ }^{1}$ MA Psychology, School of Arts and Languages, Lovely Professional University, Punjab, India

${ }^{2}$ Assistant Professor - Psychology, School of Arts and Languages, Lovely Professional University, Punjab, India *Responding Author

(C) 2016 I IA Abdullahi, P Kumar; licensee IJIP. This is an Open Access Research distributed under the terms of the Creative Commons Attribution License (http://creativecommons.org/licenses/by/2.0), which permits unrestricted use, distribution, and reproduction in any Medium, provided the original work is properly cited.
} 


\section{Gender Differences in Prosocial Behaviour}

behaviour and women are perceived more into nurturing help. That is they are more into empathetic helping, while men are mostly into chivalrous and heroic helping.

Basically in our contemporary world people are facing a lot of challenges especially poverty, insecurity, unemployment, terrorism, internal and external conflict, divorces, singlism, illiteracy etcetera virtually due to low prosocial behaviour or lack of social support from the family, relatives, friends and even community People are into abject poverty majority of the youths are unemployed and virtually living below one dollar (1.U.S.D \$) which is one of the fundamental factor responsible for the high rate of crime and negative vices bedevilling the society.

Had social support or prosocial behaviour is been effectively applied the challenges would have been minimized. In Indian context, very few studies have been conducted in the area and the present study has filled this gap and provided important insights on gender differences in prosocial behaviour in Indian population.

Penner (1995) has emphasized on social responsibility, empathetic concern, perspective taking, personal distress, altruism, other oriented moral reasoning and mutual concern moral reasoning as important factors of prosocial behaviour. Here, social responsibility refers to the duty of an individual or a person in the society or social settings which he or she is obliged to fulfil or execute. Empathetic concern denotes other oriented emotion, exhibited by and in conformity with the perceived welfare of someone in need, be it feelings of affection, sympathy, kind heartedness or compassion etc. Perspective taking refers to someone`s ability to read and understand someone's mental state, for instance thought, feelings or desire and so on. Personal distress denotes any kind of worry be it (anxiety, stress or any negative state of emotion, of another's emotional condition. Altruism refers to when someone develops the interest of helping or promoting the level of some one. Self report altruism refers to the ability to assess introspectively self as altruistic personality. Other oriented moral reasoning denotes thinking situations aimed at determining whether thing is right or wrong. Mutual concern moral reasoning refers to when two or people have the same ideology or perception with regards to a particular thing, whether it is morally right or wrong in the society.

Eisenberg and Fabes (1998) suggested that gender and culture are important indicators of pro social behaviour and they suggested females are slightly high in prosocial behaviour than males. The study of Olukayode Afolabi (2013) examines the relevance of five factor personality factors, gender difference, and emotional intelligence on prosocial behaviour in Nigeria. The results of their study indicated a significant relationship within the variables with respect to prosocial behaviour. Kumar et al. (2016) indicated that there are no significant gender differences on social relationships and adjustment. Erdle et al. (1992) also found that women tend to be on higher side on the measures of helping behaviours. Further they suggested that gender differences prevail in personality correlates of prosocial behaviour. Bihm et al. (1979) also found that females are more likely to help than males. Christopher Einolf (2001) also suggested that in general females 


\section{Gender Differences in Prosocial Behaviour}

are more prosocially motivated than males. However, some studies have also given quite opposite results. Feinman (1978) suggested on the basis of his research that men have been found more helpful than women. The studies conducted by Boice and Goldman (1981) suggested no gender differences in helping behaviour. Eagly and Crowley (1986) conducted a meta-analytic review of gender differences in prosocial behaviour and suggested that overall males helped more than females and females got more help than males. However, gender differences in prosocial behaviour were conflicting across different researches.

In Indian context, one study is conducted by Chadha and Misra (2006) and the results of their study indicated no significant influence of age, socio economic status and gender on prosocial behaviour.

\section{METHODOLOGY}

\section{Sample}

Total sixty ( $\mathrm{N}=60,30 \mathrm{M} \& 30 \mathrm{~F})$ have been selected by convenient sampling method from Lovely Professional University for this study. The age of the participants range from 20 to 30 years and the students belong to diverse disciplines including arts, humanities, science and engineering.

\section{Research Tool}

Prosocial Personality Battery (PSB) developed by Professor Lious A. Penner (1995) has been used in the current study to measure seven dimensions of prosocial behaviour. The tool consists 30 items. The dimensions include social responsibility, emphatic concern, perspective taking, personal distress, mutual moral reasoning, other oriented reasoning and self report altruism. The coefficient alphas for all the dimensions is Social Responsibility .65, Empathic Concern .67, Perspective Taking .66, Personal Distress .77, Mutual Moral Reasoning .64, Other Oriented Reasoning .77, Self-reported altruism .73, respectively.

\section{Procedure}

After selecting the sample the Prosocial Personality Battery had been given to the participants. All the important instructions were given to the participants and it was ensured that they understood all the instructions and precautions for the test. It took about 20-25 minutes to fill the battery. After collecting all the data the Independent Samples $t$ test had been administered through SPSS to analyze the data.

\section{RESULTS AND DISCUSSION}

The results of the study had been presented in Table 1. From the table we can see that on most of the dimensions including social responsibility, empathy concern, personal distress, other oriented moral reasoning, mutual concern moral reasoning, self report altruism, the t values range from .43 to 1.88 all falling below the critical value to .05 probability level i.e. 1.98 . 


\section{Gender Differences in Prosocial Behaviour}

This indicates that there is no significant gender difference on these dimensions of prosocial behaviours. The results go along with the findings of Boice and Goldman (1981) and Chadha and Misra (2006) who suggested no gender differences in prosocial behaviour.

Table 1: Means, SDs and t ratios for prosocial behaviour over the different dimensions among male and female participants

\begin{tabular}{|c|c|c|c|c|c|c|}
\hline \multirow[t]{2}{*}{ Prosocial behavior dimensions } & \multicolumn{2}{|c|}{ Male } & \multicolumn{2}{|c|}{ Female } & \multirow[t]{2}{*}{ t value } & \multirow{2}{*}{$\underset{\text { value }}{\mathbf{p}}$} \\
\hline & Mean & SD & Mean & SD & & \\
\hline Social responsibility & 22.90 & 3.754 & 21.76 & 3.43 & 1.22 & .22 \\
\hline Empathy concern & 34.50 & 4.478 & 36.40 & 4.78 & -1.58 & .11 \\
\hline Perspective taking & 14.57 & 2.176 & 15.83 & 2.61 & -2.04 & $.046^{*}$ \\
\hline Personal distress & 8.767 & 3.036 & 9.56 & 2.16 & -1.17 & .24 \\
\hline Other oriented moral reasoning & 8.934 & 3.172 & 10.33 & 2.10 & -2.01 & $.049 *$ \\
\hline Mutual concern moral reasoning & 14.30 & 4.662 & 14.83 & 4.23 & -.46 & .64 \\
\hline Self report altruism & 8.900 & 2.510 & 8.63 & 2.25 & 0.43 & .66 \\
\hline
\end{tabular}

Further, when we analyse the results of rest two dimensions i.e. perspective taking $(\mathrm{t}=2.04, \mathrm{p}<$ $.05)$ and other oriented moral reasoning $(\mathrm{t}=2.01, \mathrm{p}<.05)$, we find that on both these two dimensions female participants score on significantly higher side indicating that they are more prosocial than males. These findings go along with the studies conducted by Olukayode Afolabi (2013), Erdle et al. (1992), Bihm et al. (1979) and Christopher Einolf (2001) who all found that females are more likely to help than males. However, the findings are not supported by Feinman (1978) who found men as more helpful than women. Overall, the findings go along with the view of Eagly and Crowley (1986) who found gender differences in prosocial behaviour as conflicting across different researches.

In nutshell, we can say that more or less males and females do not differ on prosocial behaviour. However, few studies favour females over males to be more prosocial. The current study present conflicting views suggesting that on two dimensions of prosocial behaviour females are higher but on rest five they seem equal to males. As the sample size of the current study is small, more relevant inferences can be drawn by future researchers by studying large samples on measures of prosocial behaviour.

\section{Acknowledgments}

The author appreciates all those who participated in the study and helped to facilitate the research process.

\section{Conflict of Interests}

The author declared no conflict of interests. 


\section{REFERENCES}

Afolabi, O. A. (2013). Roles of personality types, emotional intelligence and gender differences on prosocial behavior. Psychological Thought, 6, 124- 139.

Bihm, E., Gaudet, I., \& Sale, O. (1979). Altruistic responses under conditions of anonymity. Journal of Social Psychology, 109, 25-30.

Boice, K., \& Goldman, M. (1981). Helping behavior as affected by type of request and identity of caller. Journal of Social Psychology, 115, 95-101.

Chadha, N. \& Misra, G. (2006). Prosocial Reasoning and Behaviour among Indian Children: A Naturalistic Study. Psychology and Developing Societies 18, 2 (2006) Sage Publications New Delhi/Thousand Oaks/London DOI: 10.1177/097133360601800202

Eagly, A. H., \& Crowley, M. (1986). Gender and helping behavior: A meta-analytic review of the social psychological literature. Psychological Bulletin, 100, 283308.

Einolf, C. J. (2001). Gender Differences in the Correlates of Volunteering and Charitable Giving.Nonprofit and Volunteering Quarterly, 40, 1092-1114.

Eisenberg, N., \& Fabes, R. A. (1998). Prosocial development. In W. Damon (Series Ed.) \& N. Eisenberg (Vol. Ed.), Handbook of child psychology, 3. Social, emotional, and personality development (5th ed., pp. 701-778). New York, NY: Wiley

Erdle, S., Sansom, M., Cole, M. R. \& Heapy, N. (1992). Sex differences in personality correlates of helping behaviour. Individual Differences, 13, 931-936

Feinman, S. (1978). When does sex affect altruistic response? Psychological Reports, 43, 1218

Kumar, P., Nabi, F., Mujoo, S., Mir, A. I., Yangchen, R., Basra, R. Abdullahi, I. A., \& Yakasai, Y. T. (2016). Social Relationships in Students' Life: Incentives or Liabilities in Mihir Kumar Mallick (Ed.), Teacher Education in $21^{\text {st }}$ Century (in press). New Delhi: New Delhi Publishers

Penner, L. A., Fritzsche, B.A., Craiger, J.P. \& Freifeld, T. R. (1995). Measuring the prosocial personality. In. J. Butcher \& C.D. Spielberger. (Eds.). Advances in personality assessment Vol. 10: 147-164. Hillsdale, New Jersey: Erlbaum.

Simo Salminen \& Timo Glad (1992) The Role of Gender in Helping Behavior, The Journal of Social Psychology, 132:1, 131-133, DOI: 10.1080/00224545.1992.9924697

How to cite this article: IA Abdullahi, P Kumar (2016), Gender Differences in Prosocial Behaviour, International Journal of Indian Psychology, Volume 3, Issue 4, No. 56, ISSN 23485396 (e), ISSN: 2349-3429 (p), DIP: 18.01.017/20160304, ISBN: 978-1-365-23992-2 